\title{
Smoking prevalence of female nurses in the national hospitals of Japan
}

\author{
Takashi Ohida, Yoneatsu Osaki, Yumiko Kobayashi, Masato Sekiyama, Masumi Minowa
}

\begin{abstract}
Objective-To estimate the prevalence of smoking and the attitudes towards the restriction of smoking at work among female nurses in the national hospitals in Japan.

Design-Questionnaires mailed to 14 randomly selected national hospitals and sanitariums in Japan in 1993.

Subjects-2207 female nurses.

Main outcome measures-Smoking status and history, and attitudes towards the restriction of smoking at work.

Results-The prevalence of smoking among female nurses was $18.6 \%$, which was higher than the age-adjusted prevalence of the general female population using this study's subjects as a standardised population. Banning smoking in the hospital in which they worked was supported by $15.0 \%$, whereas $81.6 \%$ supported the restriction of smoking.

Conclusions-The results showed that smoking is more common among female nurses than among the general female adult population. The survey suggested that nurses favour restriction, but not banning, of smoking.

(Tobacco Control 1999;8:192-195)
\end{abstract}

Keywords: smoking prevalence; nurses; Japan

\section{Introduction}

Although the prevalence of smoking among physicians has been reported to be lower than that of the general population in Japan, ${ }^{1}$ the prevalence of smoking among female nurses has been reported to be higher than that of the general female population. ${ }^{2-6}$ The higher prevalence of smoking among nurses is a global trend. ${ }^{6}$ The World Health Organisation (WHO), however, has called for further recognition among medical professionals of the problems that smoking brings to their own field and their responsibility in terms of personal conduct and appropriate practice.

Although anti-smoking campaigns in which nurses have participated have been successful in the United States and Canada, ${ }^{6}$ and the prevalence of smoking in nurses has decreased as much as in other health workers, no such claims have yet been made in Japan. Nurses who quit smoking fulfil their function as health educators well, and in the United States and the United Kingdom, studies have evaluated the effectiveness of teaching nurses how to give smoking cessation advice and how to implement it themselves. ${ }^{7-9}$
Although these facts have been reported in the Japanese medical community, there has been no nationwide survey on the prevalence of smoking among nurses in Japan.

Padula $^{10}$ stressed the importance of surveying smoking prevalence among nurses who have been charged with the health education of patients. Davis ${ }^{11}$ suggested that when smoking prevalence among the medical profession falls below that of the general population, after several decades the prevalence in the general population would also decrease. In view of this, we considered it important to survey smoking prevalence among nurses in Japan.

To contribute to the effectiveness of anti-smoking campaigns targeting medical professionals, we conducted a survey on the prevalence of and attitudes towards smoking among nurses.

\section{Methods}

SAMPLE

Subjects were male and female nurses working at 15 institutions randomly selected from the 256 national hospitals and sanitariums all over the country. Although all 15 institutions responded, one institution did not follow the specified procedure for collecting questionnaires and was excluded from the analysis.

PROCEDURE

The survey period was between January and February 1993. Questionnaires were distributed with the permission and cooperation of the hospital's director and either the director of nursing or the general supervisor of nursing at each of the chosen hospitals. In each institution the administration and collection of surveys was handled by the director of nursing or the general supervising nurse. The questionnaires were collected within one week of distribution.

Each subject was given a questionnaire and two envelopes (one large and one small). After completion, the questionnaire was placed in the small envelope, which was put in the large envelope. The large envelope, which was then collected, had the respondent's name. Only the small envelopes, without the respondents' names, were returned to our team. We used this procedure to ensure anonymity, and to prevent anyone from recognising the smoking status of specific nurses. The director of nursing or the general supervisor nurse could also try to improve the response rate by encouraging those subjects who had not yet submitted their questionnaire. 
Table 1 Prevalence of smoking in female nurses in 14 hospitals

\begin{tabular}{|c|c|c|c|c|c|c|}
\hline $\begin{array}{l}\text { Hospital } \\
\text { (number of nurses) }\end{array}$ & $\begin{array}{l}\text { Smoking } \\
\text { prevalence }^{\star}(\%)\end{array}$ & $\begin{array}{l}\text { Patients } \dagger \text { per } \\
\text { nurse (per day) }\end{array}$ & $\begin{array}{l}\text { Hospital beds } \\
(n)\end{array}$ & $\begin{array}{l}\text { Beds occupancy } \\
\text { rate (\%) }\end{array}$ & $\begin{array}{l}\text { Revenuel } \\
\text { expenditure } \ddagger\end{array}$ & $\begin{array}{l}\text { Population } \\
\text { (thousands) }\end{array}$ \\
\hline $1(173)$ & 8.4 & 7.3 & 344 & 87.4 & 1.00 & 263 \\
\hline $2(152)$ & 10.9 & 4.4 & 300 & 80.3 & 1.06 & 537 \\
\hline $3(238)$ & 12.2 & 5.7 & 585 & 86.6 & 1.09 & 594 \\
\hline $4(165)$ & 12.9 & 6.6 & 465 & 84.5 & 1.03 & 20 \\
\hline $5(69)$ & 14.5 & 5.4 & 147 & 75.7 & 0.70 & 548 \\
\hline $6(84)$ & 17.0 & 5.5 & 250 & 77.1 & 1.03 & 47 \\
\hline $7(221)$ & 17.4 & 3.5 & 650 & 76.6 & 0.98 & 66 \\
\hline $8(193)$ & 19.5 & 3.9 & 460 & 89.6 & 0.99 & 170 \\
\hline 9 (137) & 21.0 & 3.5 & 430 & 94.3 & 0.95 & 20 \\
\hline $10(150)$ & 24.1 & 3.2 & 400 & 87.0 & 1.02 & 49 \\
\hline $11(224)$ & 24.9 & 6.3 & 435 & 87.7 & 0.95 & 3220 \\
\hline $12(98)$ & 26.1 & 2.8 & 300 & 89.5 & 0.76 & 71 \\
\hline $13(176)$ & 27.7 & 3.7 & 455 & 90.4 & 1.00 & 32 \\
\hline $14(127)$ & 28.3 & 4.1 & 315 & 90.5 & 1.02 & 15 \\
\hline Mean (SD) & 18.6 & $4.7(1.4)$ & 395 (131.9) & $85.5(5.9)$ & $0.97(0.11)$ & 404 (839) \\
\hline \multicolumn{7}{|c|}{ National hospitals (not sampled, $\mathrm{n}=242$ ) } \\
\hline \multirow{3}{*}{\multicolumn{2}{|c|}{$\begin{array}{l}\text { Mean (SD) } \\
t \text { value } \\
\mathrm{p} \text { value for } t \text { test }\end{array}$}} & $4.8(1.7)$ & $338(171.5)$ & $82.8(13.9)$ & $0.93(0.14)$ & $425(1280)$ \\
\hline & & -0.10 & 1.23 & 0.73 & -0.98 & 0.06 \\
\hline & & 0.92 & 0.22 & 0.47 & 0.32 & 0.95 \\
\hline \multirow{2}{*}{\multicolumn{2}{|c|}{$\begin{array}{l}\mathrm{CC} \\
\mathrm{p} \text { value for } \mathrm{cc} \$\end{array}$}} & -0.61 & 0.05 & 0.51 & -0.19 & 0.09 \\
\hline & & 0.02 & 0.99 & 0.07 & 0.51 & 0.75 \\
\hline
\end{tabular}

$\mathrm{CC}=$ correlation coefficient for smoking prevalence and each variable.

${ }^{\star}$ Smoking prevalence $=($ daily smoker + occasional smoker $) /$ number of responders. Prevalence in each hospital is age-adjusted using total subjects as a standardised population.

†Patients $=$ inpatients + outpatients.

$\ddagger$ Population = population of municipality where each hospital is located.

SUsing null hypothesis that correlation is equal to zero.

MEASURES

As few surveys on the smoking prevalence of nurses have been conducted in Japan, we constructed a new questionnaire for surveying smoking in nurses, consisting of 29 questions. There were six personal background items and 13 items translated from the WHO guidelines, ${ }^{12}$ adjusted to reflect circumstances in Japan. The remaining 10 items were newly drafted using those in the questionnaire drawn up by Mori for reference. ${ }^{13}$

The survey covered the following areas.

- Smoking status and history

- Experience with and attitude to quitting smoking

- Knowledge on smoking and health (diseases)

- Opinions about smoking of women or nursing staff

- Personal factors such as sex, age, position, nursing certificate, and family status

- Feelings about occupation and professional satisfaction.

The total number of nurses from the 14 institutions was 2360. Of these, six refused to reply or returned a blank sheet, and 57 returned incomplete questionnaires-for example, omitting sex or age information, leaving 2297 responses $(97.3 \%)$. There were 90 replies from male nurses, but because the sample size was small, it was decided to omit these; consequently the analysis was conducted on the 2207 replies from female nurses. Of these, $2025(91.8 \%)$ responded to all 29 items on the list.

\section{REPRESENTATIVENESS}

All national hospitals and 14 selected national

hospitals

We calculated the mean and standard deviation of the five variables (listed in columns 3-7 of table 1) for the group of 14 randomly sampled hospitals and for the 242 national hospitals not sampled, using data from the Department of
National Hospitals, Health Services Bureau, Ministry of Health and Welfare. We used a $t$ test to examine any significant difference between these two groups (table 1), to prove that the 14 selected national hospitals were representative.

Working conditions of nurses in national hospitals compared with all nurses in fapan

A comparison of the working conditions of all nurses in Japan (group A), and those in national hospitals (group B), based on the 1993 survey $^{14}$ by the Japanese Nursing Association of working conditions of nurses in national hospitals $(35000)$ and all working nurses (860 000), showed that their working conditions were almost the same in terms of average ages (A: 35.7 years, B: 36.4 years), working hours per week (A: 41 hours 23 minutes, B: 39 hours 41 minutes) and monthly salary (A: 330000 yen, B: 345000 yen).

A comparison of variables related to smoking behaviour revealed that the percentages who replied "Satisfied" to the question about the degree of vocational satisfaction were $35.0 \% \quad(\mathrm{~A})$ and $37.0 \% \quad(\mathrm{~B})$, that the percentages of nurses in the departments of psychiatry versus all working nurses were $6.9 \%$ (A) and $6.4 \%(B)$, and that the percentages of licenced practical nurses (LPN) versus all working nurses were $44.6 \%$ (A) and $18.7 \%$ (B), respectively. (There are two types of nursing certificates in Japan: licenced practical nurses (LPNs) who complete a two-year programme after junior high school (17 years and above), and registered nurses (RNs) who complete a three-year programme after completing senior high school (21 years and above).) Not surprisingly, scholastic ability tends to be higher in RNs (personal communication with the director of nursing division, Health Policy Bureau, Ministry of Health and Welfare). 
DEFINITION

The prevalence of smoking was calculated as follows:

Prevalence $(\%)=$ (daily smokers + occasional smokers)/number of responders. "Occasional" smokers were current smokers who did not smoke every day.

Age-adjusted prevalence in each hospital was calculated using the total number of subjects as a standardised population (table 1).

COMPARISON WITH THE GENERAL POPULATION There are two surveys on the prevalence of smoking among the general population in Japan. We compared the result of our survey with that from a survey conducted by Japan Tobacco Industry Inc $^{15}$ and a national nutrition survey conducted by the Ministry of Health and Welfare. ${ }^{16}$ The prevalence of smoking in these studies was age-adjusted using the subjects of this study as a standardised population.

\section{Results}

REPRESENTATIVENESS

Table 1 shows that no statistically significant difference was evident between the two groups in terms of our five variables. The age-adjusted prevalence of smoking at the 14 hospitals ranged from $8.4 \%$ to $28.3 \%$. When the correlation coefficients between the five variables and the age-adjusted prevalence of smoking were examined, the only variable showing a significant difference was number of patients per nurse.

SMOKING PREVALENCE AMONG FEMALE NURSES The prevalence of smoking among female nurses was $18.6 \%$, which was higher than the rates of the two studies in the general female population. ${ }^{15}{ }^{16}$ The age-adjusted prevalence of smoking in the survey by Japan Tobacco Industry Inc in 1992 was $15.4 \%$, and that of the national nutrition survey in 1992 was $10.3 \%$.

TYPES OF CERTIFICATE

When analysed by the type of nursing certificate, smoking prevalence was higher among LPNs than among $\mathrm{RNs}(28.8 \%$ v $16.3 \%)$.

SATISFACTION WITH CAREER CHOICE

Smoking was more prevalent among nurses who were not satisfied with their career choice $(32.0 \%)$ than among those who stated that they were happy to be nurses $(17.3 \%)$.

\section{DEPARTMENT}

Smoking was more common among nurses in the departments of psychiatry $(27.7 \%)$, than in the departments of pediatrics $(16.1 \%)$.

ATTITUDES ABOUT RESTRICTING SMOKING

The banning of smoking in the hospital to which they belonged was supported by $15.0 \%$, and $81.6 \%$ supported restricting smoking ( $\mathrm{n}=$ 2167).

\section{Discussion}

The representativeness of the 14 hospitals sampled was considered to ensure (a) that there was no statistically significant difference between the mean values of the variables of the sampled hospitals and those of the 242 hospitals not sampled, and (b) to ensure the 14 hospitals selected were randomly sampled.

When compared with the figure for age-adjusted prevalence of smoking among the general population published in the Japan Tobacco Industry Inc survey, the figures for age-adjusted prevalence of smoking were found to be higher at nine of the 14 hospitals sampled in our survey, and when compared with the figure in the national nutrition survey, the figures for age-adjusted prevalence of smoking were higher than among the general population at 13 of the 14 hospitals sampled. The analysis suggests a higher prevalence of smoking (18.6\%) among nursing staff than among the general adult population.

When comparing three variables (percentage of LPNs, percentage of nurses in the psychiatry department, degree of vocational satisfaction) assumed to be related to the smoking behaviour of nurses in this study, the percentage of LPNs in national hospitals was lower than that in all working nurses, whereas the percentages for the other two variables were similar. The working conditions of the two groups of nurses were also similar. We believe, therefore, that the prevalence of smoking among all working nurses is somewhat higher than among nurses in national hospitals, if the percentage of LPNs is taken into consideration.

There was wide variation in the age-adjusted prevalence of smoking at the 14 hospitals. The correlation between the five variables and the age-adjusted prevalence of smoking indicated that smoking was less common in hospitals where the number of patients per nurse was greater. Adriaanse ${ }^{6}$ found that the prevalence of smoking among highly motivated nurses was lower-this may be a factor in our findings. In our survey, however, information on the status of measures to prevent smoking inside the hospital, whether or not smoking education was provided, and on the smoking behaviour of the directors of national hospitals and the directors of nursing was not available. We believe the correlation between these background factors and the prevalence of smoking should be studied in the future. The prevalence of smoking among nurses in the United States and Canada is reported to have declined as a result of smoking cessation education in the hospital. ${ }^{6}$ The above effects, including measures to prevent smoking inside the hospital, may have been a factor in the wide variation in the prevalence of smoking at 14 hospitals.

The location of the national hospitals is another problem. Many national hospitals were once army hospitals or tuberculosis hospitals before the end of the second world war, so few are located in large cities. A study by Kobayashi ${ }^{17}$ complemented our survey. That study, which investigated the smoking prevalence among nursing staff in four 
national, highly advanced medical institutions in Tokyo and Osaka, revealed that the smoking prevalence among nurses was $20.3 \%$, slightly higher than our results. However, our survey did not show a statistically significant correlation between the age-adjusted prevalence of smoking at the 14 hospitals and the populations of the municipalities where the hospitals are located. Surveys of clinics with a small number of nurses and on non-national institutions are therefore necessary to assess the situation in the whole nursing population.

Many have reported stress as a factor involved in the smoking behaviour of nurses. ${ }^{18-21}$ Smoking was more common in those working in the departments of psychiatry than in other departments. Wagner ${ }^{21}$ also pointed out that there are factors that increase smoking prevalence among nurses in psychiatric work environments. These factors, including their relationship with stress, need to be determined.

Support for smoking cessation by physicians has developed because of occupational mission, social demand, and improved knowledge, whereas that by nurses in Japan remains an unanswered challenge. ${ }^{1}$ Smoking cessation programmes should be incorporated into nursing education and in-hospital education. $^{22} 23$

We wish to express our thanks to the directors of national hospitals and sanitariums, and the directors of nursing (or the general supervisor nurses) for their cooperation in the survey, and to Shuji Hashimoto for his helpful suggestions on statistical methods. The survey reported in this paper was supported by a grant for health science given by the Health Administration and grant for health science give
Science Project in 1992 .

1 Mori T. Smoking among medical professionals. Nippon Koshu Eisei Zasshi 1993;40:71-3. (In Japanese)

2 Kawane $H$, Soejima R Smoking among the staff of a medical school hospital. In: Aoki M, Hisamich S, Tominaga S, eds. Smoking and health. Proceedings of the sixth world conference on smoking and health, Tokyo, 9-12 November 1981 Amsterdam: Excerpta Medica, 1988:685-7.
3 Oshima A, Nakamura M. Cigarette smoking among some occupational groups in Osaka Prefecture. Nippon Koshu occupational groups in Osaka Prefecture.
Eisei Zasshi 1988;35:527-30. (In Japanese)

4 Hay DR. The smoking habits of nurses in New Zealand: results from the 1976 population census. NZ Med F 1980; 672:391-3.

5 Sacker A. Smoking habits of nurses and midwives. $\mathcal{F} A d v$ Nurs 1990;15:1341-6.

6 Adriaanse H, Van Reek J, Zandbelt L, et al. Nurses' smoking worldwide: a review of 73 surveys of nurses' tobacco con-
sumption in 21 countries in the period 1959-1988. Int $\mathcal{F}$ Nurs Stud 1991;28:361-75.

7 Clark JM, Rowe K, Jones K. Evaluation of the effectiveness of the coronary care nurses' role in smoking cessation. $\mathcal{f}$ Clin Nurs 1993;2:313-22.

8 Hollis JF, Lichtenstein E, Vogt TM, et al. Nurse-assisted counseling for smokers in primary care. Ann Intern Med 1993;118:521-5.

9 Reeve K, Adams J, Kouzekanani K. The nurses as exemplar: smoking status as a predictor of attitude toward smoking smoking status as a predictor of attitude toward s
and smoking cessation. Cancer Pract 1996;4:31-3.

10 Padula CA. Nurses and smoking: review and implications. $f$ Prof Nurs 1992;8:120-32.

11 Davis RM. When doctors smoke. Tobacco Control 1993; 2:187-8.

12 Working Group on Tobacco or Health. Guidelines for the conduct of tobacco-smoking surveys among health professionals. Tokyo: World Health Organisation Regional Office for Western Pacific, 1987;9-19.

13 Mori T. A survey on the smoking status of nurses. Kankyocho Itaku Gyoumu Kenkyu. Tokyo: Environment Agency, 1987:5-18. (In Japanese)

14 Japanese Nursing Association. Research report no 45. Report on the status of nursing personnel. Tokyo: Japanese Nursing Association, 1995. (In Japanese)

15 Anon. Nationwide cigarette smoking survey in 1995. Tokyo: Japan Tobacco Industry Inc., 1995. (In Japanese)

16 Statistics and Information Department, Minister's Secretariat, Ministry of Health and Welfare. National nutrition survey. Tokyo: Health and Welfare Statistics Association, 1993. (In Japanese)

17 Kobayashi, Y. Problems of smoking by nurses: health services - the door to a world without cigarettes. Tokyo: Hoken Dojin Sha, 1993. (In Japanese)

18 Tagliacozzo R, Vaughn S. Stress and smoking in hospital nurses. Am f Public Health 1982;72:441-8.

19 Murray M, Swan AV, Mattar N. The task of nursing and the risk of smoking. $\mathcal{F}$ Adv Nurs 1983;20:553-7.

20 DeMello DJ. Smoking and attitudes toward smoking among clinical nurse specialists, critical care nurses, and medicalsurgical nurses. Oncol Nurs Forum 1989;16:795-9.

21 Wagner TJ. Smoking behavior of nurses in western New York. Nurs Res 1985;34:58-60.

22 Becker DM, Myers AH, Sacci M, et al. Smoking behavior and attitudes toward smoking among hospital nurses. $\mathrm{Am}$ f Public Health 1986;76:1449-51.

23 Dore K, Hoey J. Smoking practices, knowledge and attitudes regarding smoking of university hospital nurses. Can f Public Health 1988;79:170-4. 